\title{
CAN BITCOIN BE A SAFE HAVEN IN FEAR SENTIMENT?
}

\author{
Chi-Wei SU${ }^{1}$, Yuan $\mathrm{XI}^{1}$, Ran $\mathrm{TAO}^{1,2^{*}}$, Muhammad $\mathrm{UMAR}^{1}$ \\ ${ }^{1}$ School of Economics, Qingdao University, Qingdao, Shandong, China \\ ${ }^{2}$ Qingdao Municipal Center for Disease Control and Preventation, Qingdao, Shandong, China
}

Received 01 February 2021; accepted 20 June 2021; first published online 18 January 2022

\begin{abstract}
This paper explores how fear sentiment affects the price of Bitcoin by employing the rolling-window Granger causality tests. The analysis reveals negative influences from the volatility index (VIX) to Bitcoin price (BTC), which ascertains that Bitcoin can not be considered a haven in fear sentiment. Due to the liquidity in economic downside risks, BTC may decrease with high VIX to hedge losses, increasing during low VIX periods. The empirical results conflict with the intertemporal capital asset pricing model, which underlines that the increasing VIX can promote the price of Bitcoin. In turn, BTC positively impacts VIX, which shows that Bitcoin price can be treated as the main indicator for a more comprehensive analysis of the fear index. Under severe global uncertainty and changeable fluctuation of market sentiment, investors can optimize investment decisions based on market fear sentiment. The government can also consider VIX to grasp the trend of BTC to participate in cryptocurrency speculation effectively.
\end{abstract}

Keywords: Bitcoin price, volatility index, causal relationship, time-varying.

JEL Classification: C32, G12, E66.

\section{Introduction}

This paper aims to discuss the interaction between fear sentiment and cryptocurrencies, to ascertain how Bitcoin prices (BTC) behave during a turbulent period of panic. Bitcoin, as the first cryptocurrency to be traded, is created by Satoshi Nakamoto in 2008 (Harvey, 2014). The surge of Bitcoin prices and the huge increase in the associated market's capitalization attract many investors (Kristoufek, 2015). Since then, Bitcoin has become a hot topic in finance, especially when considering investment sentiment. Since Keynes (1936) invented the "animal spirits," investor sentiment has been an elusive concept, attracting market participants' widespread attention. The classical financial theory presents that the competition between rational investors determines the equilibrium asset price.

The asset price reflects the basic value, which is determined by the discounted value of expected cash flows. While the surge in fear sentiment is prone to irrational decline in the

\footnotetext{
${ }^{\star}$ Corresponding author. E-mail: taotao0212@163.com
} 
market. Irrational investor behaviour or sentiment can cause asset prices to deviate from the reasonable price of their underlying fundamentals, and Black (1986) refers to such irrational and uninformed traders as "noise" traders. Over time, they will eventually suffer enough losses and then be forced to withdraw from the market. Therefore, understanding what the role of sentiment is, choosing a suitable measure of sentiment, and quantifying the effect of sentiment on BTC is a worthy topic to research. For investors, if the price of Bitcoin does not properly reflect the fundamental value, it may lead to mistakes in portfolio allocation decisions, which will cause them to face property losses. As governments (such as Bulgaria, Israel, the United States) include Bitcoin in their asset reserves, the unexpected fluctuations will also cause difficulties for central banks and government agencies' policy decisions in various countries. In this paper, we aim to study the dynamic process of sentiment changes on BTC. Because it can reflect investors' expectations of future stock price fluctuations and can observe the psychological performance of option participants, the market volatility index (VIX) is also known as an investor fear gauge (Smales, 2019). We explore a novel data-VIX source to investigate whether Bitcoin can be a haven in fear sentiment.

Although Bitcoin is originally established as an electronic currency, with the increase in institutional participation, it has been regarded as an asset (Baur et al., 2018). Based on this, several studies analyze the hedging properties of Bitcoin and its transmission mechanism with VIX (Bouri et al., 2017a; Al-Yahyaee et al., 2019; Troster et al., 2019; Jareño et al., 2020). Weber (2014) argues that after the global financial crisis in 2008, Bitcoin has risen rapidly as an asset substitute and still can be regarded as a hedge against currency depreciation and economic uncertainty. Because Bitcoin evidence a low correlation with traditional mainstream assets (such as stocks and bonds) and alternative investments (including hedge fund, real estate and over-the-counter derivatives, etc.) (Brière et al., 2015). A high degree of uncertainty and a challenging economic environment may force investors to switch from traditional assets to Bitcoin (Bouri et al., 2017b). Hence, under the extreme market conditions of investment in stock markets, Bitcoin, known as a "digital gold" with hedging properties (Popper, 2015), can also be regarded as a safe-haven asset (Shahzad et al., 2019). Moreover, Dyhrberg (2016a) and Guesmi et al. (2019) believe that Bitcoin effectively improves the risk and return on the investment portfolio, because they find that Bitcoin exhibits a negative correlation with other financial assets, including gold, the U.S. dollar, and the stock indexes of some countries. Chan et al. (2019) find favourable evidence that Bitcoin is a powerful hedging instrument against S\&P indices. Meanwhile, Platanakis and Urquhart (2020) find that add cryptocurrencies to investment portfolio will bring higher risk-adjusted returns. BTC remains resilient during stress periods, indicating the hedging potential of Bitcoin (Bouri et al., 2018a). Therefore, during the high VIX period, the market fears sentiment is heating up, and the public will be more pessimistic about the prospects, resulting in increased demand for safe assets to cope with future downside risk (Karalevicius et al., 2018; LópezCabarcos et al., 2021). This has led to the expansion of trading volume in the Bitcoin trading market. Moreover, Dyhrberg (2016b) and Guesmi et al. (2019) find that Bitcoin exhibits a negative correlation with other assets, including gold, the US dollar, and the stock indexes of some countries, which contributes to reducing portfolio risk. Under the extreme market conditions of investment in stock markets, Bitcoin, known as a "digital gold" with hedging properties, has emerged as a safe-haven (Shahzad et al., 2019). 
Meanwhile, Al-Yahyaee et al. (2019) determine that geopolitical risks (GPR) can affect the VIX and BTC's co-movements. Whereas, there are some studies that Bitcoin is correlated with the uncertainty of the market measured by the VIX index, which serves as a valuable reference to investors. However, there are still some doubts about the safe-haven properties of Bitcoin. Yermack (2013) classifies Bitcoin as a speculative investment, which has inherent risk attributes due to its extreme volatility (Cheah \& Fry, 2015). Da et al. (2015) construct a search-based investor attitude index and suggest that negative sentiment will affect returns. The spread of scare will lead to a sharp decline in asset (such as Bitcoin) prices and exacerbate market turmoil (Ali et al., 2020). Conlon and McGee (2020) evaluate the performance of Bitcoin in the financial crisis and find that it fails to play a safe-haven role during severe financial turmoil. Jareño et al. (2020) point out that VIX presents a negative impact on BTC in most periods. Given that the information provided by the VIX is widely accounted for by investors in their risk management strategies, VIX must be considered to verify Bitcoin's hedging ability or relationship with other assets (Bouri et al., 2017c).

This study makes several contributions to the related literature on BTC. Firstly, this paper explores its hedging properties by studying Bitcoin price dynamics under extreme events (Wang et al., 2019). Hence, understanding the mutual influences between BTC and fear can provide investors with ideas for portfolio management or risk management to deal with economic downside risks. Secondly, investment choices depend largely on investor sentiment changes, so the sentiment is also a driving factor for Bitcoin price fluctuations, especially during economic downturns. However, the measurement of fear sentiment has mostly applied dummy variables (Georgoula et al., 2015; Kjærland et al., 2018; Dastgir et al., 2019) in the previous studies. These variables do not reflect the overall sentiment well and correctly. Thus, we choose VIX to serve as the market fear sentiment and verify Bitcoin's hedging ability under downside risks. Third, the previous studies neglect the time-varying nature of model parameters, which shows the non-fixed relationship of BTC with the fear sentiment (Al-Yahyaee et al., 2019; Jareño et al., 2020), and we attempt to make up for the gaps in the interaction between VIX and BTC by performing tests of bootstrap rolling window causality. The empirical result illustrates that Bitcoin fails to act as a hedge asset in fear sentiment, and it is contrary to the intertemporal capital asset pricing model (ICAPM), which indicates that these two variables have a positive relationship. In turn, there is a positive influence from BTC to VIX. The government can consider VIX as a tool to grasp BTC's trend to promote the progress of encryption technology further to strengthen supervision to prevent potential security risks of Bitcoin.

Moreover, the interrelationship between VIX and BTC provides investors with a reflection to maintain returns at risk of economic uncertainty. During the period with high VIX, investors tend to escape from the Bitcoin market in time and resort to more liquid assets (such as gold) to optimize their investment. Besides, the Bitcoin market is an important indicator that reflects the macroeconomy and investor sentiment.

The organization of this paper is as follows. The literature review on this topic is presented in Section 1. The introduction of the general equilibrium model with VIX and BTC is in Section 2. Section 3 describes the relevant methodology. The Bitcoin price data and the volatility index used in this paper are discussed in Section 4. In Section 5, we focus on the analysis of the empirical result. The last section provides concluding remarks. 


\section{Literature review}

Bitcoin is born as a decentralized payment system in 2009, and then considered as an investment tool, showing predictability in its price formation, Following its inception in 2009 as a decentralized payment system and subsequent use as an investment vehicle, Bitcoin, showing predictability in its price formation (Atsalakis et al., 2019). There is evidence that Bitcoin is predictable by some external variables. Philippas et al. (2019) indicate that the attention of online social media helps to push the price of Bitcoin to rise, which proves the sensitivity of BTC to the sentiment tendency of information (Jubinski \& Lipton, 2012). El Alaoui et al. (2019) prove that Bitcoin prices changes and changes in transaction volume changes mutually interact in a nonlinear manner. Balcilar et al. (2017) show the probability of predicting BTC changes according to price indices and gold prices. Su et al. (2021a) underline that high U.S. partisan conflict will promote BTC, to deal with potential political risks and uncertainties. Demir et al. (2018), Bouri and Gupta (2021) analyze that economic policy uncertainty presents predictable characteristics to Bitcoin. Su et al. (2020a) analysis revealed that shocks that originated in oil price will transmit to Bitcoin price. Al Mamun et al. (2020) investigate the role of geopolitical risk on the Bitcoin market and find it will have an impact on the correlation structure between Bitcoin and other assets. Bouri et al. (2019) prove that the increase in uncertainty associated with the intensification of trade frictions often contributes to the rise of BTC. To expand the relevant literature, this study focuses on the performance of Bitcoin in fear sentiment.

Some studies point out that investor sentiment changes will largely guide investment choices (Nofsinger, 2005; Bollen et al., 2011; Guo et al., 2017). Kristoufek (2015) concludes that Bitcoin prices are driven by the investor's interest in the cryptocurrency. Bukovina and Martiček (2016) devote to the economic principles between sentiment and Bitcoin, examining the sentiment as a driver for BTC volatility. Investor sentiment easily promotes Bitcoin price compared to basic economic factors (Baek \& Elbeck, 2015). Zouaoui et al. (2011) evidence that the financial market involving fewer institutional investors participation are more sensitive to sentiment swings. Compared with mainstream asset classes, the Bitcoin market is still in its infancy, with lower liquidity, higher transaction costs, and lower participation by institutional investors (Kharpal, 2017; Shevchenko \& Godwin, 2018). That means that Bitcoin will exhibit greater sensitivity to sentiment than mature assets (such as gold, stock market, etc.). Hence, investor sentiment is also one of the important factors affecting the trend of Bitcoin prices. Kristoufek (2013) and Celeste et al. (2018) discover a potential herding effect and anchoring behaviour among investors in the Bitcoin market. These studies lay the foundation for investment behaviour in the Bitcoin market based on sentiment analysis, which will directly reflect on BTC. In the context of global trade frictions, Bouri et al. (2021) indicate that investors can view Bitcoin as a hedge against trade-related uncertainties. Ciner et al. (2013) discover that under the financial turmoil, there are often unstable dynamic changes between markets, so the hedging properties of the underlying risky assets should also be examined under fear and uncertainty. Meanwhile, Bouri et al. (2018b) confirm that the global financial stress index has a significant causal relationship to BTC. Plakandaras et al. (2021) suggest that trade uncertainty will not have an impact on Bitcoin prices. Ciaian et al. (2016) explore the safe haven properties of Bitcoin, revealing that it can be viewed as 
a short-term tool for hedging for stocks and the dollar. Using VIX that integrates the stock markets of 14 countries, Bouri et al. (2017d) consider that Bitcoin can store as a hedge asset. Georgoula et al. (2015) detect the positive relation between market sentiment and the BTC. Based on the positive correlation with stock indexes, Poyser (2019) discusses the benefit of Bitcoin as a speculative or safe-haven asset. Bouoiyour et al. (2019) believe that Bitcoin can be used as a hedging tool to withstand the decline in the US stock market in the short term find that Bitcoin can serve as a safe haven against US stock losses but only in the short term. Al-Yahyaee et al. (2019) ascertain a positive linkage between VIX and BTC, which confirms the importance of Bitcoin in hedging effectiveness and reducing downside risks.

However, Bitcoin's safe-haven properties in fear sentiment are not always supported. Yermack (2013) suggests that Bitcoin behaves more like a risky asset than alternative currencies, so it is not conducive to risk management and challenging for investors to hedge risks. Bouri et al. (2017c) evidence a negative correlation between VIX and BTC. Bitcoin, as a virtual asset, has inherent risk attributes, which are mainly reflected in the lack of supervision and hacker threats, so it cannot hedge against the US market (Stavroyiannis \& Babalos, 2017). Matkovskyy and Jalan (2019) indicate that rational investors tend to shift from the speculative Bitcoin markets to highly liquid assets in crisis periods when the market fear sentiment is high. Smales (2019) points out Bitcoin market has yet to mature, it is not reliable to consider Bitcoin as a hedge given the financial crisis that accompanies the spread of fear sentiment. Jareño et al. (2020) argue that VIX has shown negative and significant effects on BTC. Therefore, it cannot serve as a hedge against a financial crisis. Qin et al. (2020) suggest that Bitcoin has the characteristics of instability, which indicates that it should not always be considered as an asset to hedge the risk of global uncertainty. Chen et al. (2020) indicate that fear sentiment will exacerbate market turbulence, explaining the decline of Bitcoin earnings and an increase in transaction volume. Al Mamun et al. (2020) find that policy uncertainty and deteriorating economic conditions are accompanied by increasing market fear sentiment, and Bitcoin investors can only turn to gold to avoid risks.

A safe-haven asset is defined as a financial instrument that is irrelevant or negatively related to the overall economy and can be expected to maintain or even increase in value during economic downturns (Baur \& Lucey, 2010), so it is important to investors in a market crash. During the periods of crisis, usually accompanied by a sharp drop in asset prices, fear sentiment will dominate investor behaviour and drive them to give up risky (lower liquidity) securities and choose safer (higher liquidity) assets, such as cash, government bonds, and gold (Kindleberger, 1978). Therefore, when testing the hedging effect of assets, we must consider the elements of its liquidity. Considering whether Bitcoin can encounter severe market downsides risk under the fear sentiment, it is crucial to analyze its hedge ability. The literature on BTC has focused on this issue, but the results are mixed. While Bouri et al. (2017a) and Jareño et al. (2020) doubt Bitcoin's hedging ability due to the negative correlation between VIX and BTC. While, Georgoula et al. (2015) find a positive correlation between fear sentiment and the BTC, and Al-Yahyaee et al. (2019) confirm the importance of BTC in hedging downside risks.

In summary, the effect of fear sentiment on the price of Bitcoin is unclear, and there is the question of whether Bitcoin can be a safe haven in fear sentiment. This paper aims to investigate whether there is any indication that Bitcoin can serve as a safe haven to deal with market 
turmoil by studying the trend of BTC from 2010 to 2020. It is then possible to question what impact will the fluctuation of Bitcoin price have on market sentiment. The existing studies ignore the time-varying interaction between VIX and BTC, which will cause the Granger causality to be not constant. Therefore, we apply the bootstrap sub-sample rolling-window causality test to enhance the accuracy of the results. Further study of the impact of VIX on BTC will evidence whether Bitcoin can be considered as a safe haven asset in fear sentiment. In turn, the influence from BTC to VIX can provide a new tool to predict the market investor sentiment based on the Bitcoin market.

\section{Intertemporal capital asset pricing model}

We apply the intertemporal capital asset pricing model (ICAPM), created by Merton (1973), to explore the interaction between VIX and BTC. The general assumption is that there are two investors in the Bitcoin market, and VIX measures the systemic risk. First of all, the model focuses on informed traders, who consider dynamics of risk-return and predict the trend of BTC based on VIX. Accordingly, the amount of Bitcoin to hold can be shown as Equation (1):

$$
I_{t}^{d}=\frac{E_{t-1}\left(\mathrm{BTC}_{t}\right)-\mathrm{VIX}^{f}}{\mu\left(\mathrm{VIX}_{t}\right)},
$$

where the percentage of Bitcoin held by the informed investors is represented by $I_{t}^{d}$ at time t. $\mu\left(\mathrm{VIX}_{t}\right)>0$ implies that the value is greater than 0 , and $\mu^{\prime}\left(\mathrm{VIX}_{t}\right)>0$ refers to that this is a monotonically increasing function. $\mathrm{BTC}^{f}$ is Bitcoin price when the value of VIX is 0 . $E_{t-1}\left(\mathrm{BTC}_{t}\right)$ is a conditional expectation of BTC according to the information in the $t-1$ period. $\mathrm{BTC}_{t}$ is an ex-post $\mathrm{BTC}$ during the $t$ period. Assume that the market of Bitcoin only has informed investors, then the value of $I_{t}^{d}$ is 1 . Thereby, we can rewrite Equation (1) to the capital asset pricing model (CAPM), which is developed by Sharpe (1964), as Equation (2):

$$
E_{t-1}\left(\mathrm{BTC}_{t}\right)=\mathrm{BTC}^{f}+\mu\left(\mathrm{VIX}_{t}\right) .
$$

It is clearly observed that the VIX has a positive effect on BTC, which also displays that Bitcoin has the attributes of a safe haven in fear sentiment. Next, we consider another kind of investor: feedback traders. So, the amount of Bitcoin purchased by feedback traders is as follow:

$$
F_{t}^{d}=\gamma \mathrm{BTC}_{t-1},
$$

where $\gamma>0$. Consider adding feedback investors to the model, we have $I_{t}^{d}=1-F_{t}^{d}$, then Equation (4) can be generated by transforming Equation (1):

$$
E_{t-1}\left(\mathrm{BTC}_{t}\right)=\mathrm{BTC}^{f}+\mu\left(\mathrm{VIX}_{t}\right)-\gamma \mu\left(\mathrm{VIX}_{t}\right) \mathrm{BTC}_{t-1} .
$$

In Equation (4), the item of $-\gamma \mu\left(\mathrm{VIX}_{t}\right) \mathrm{BTC}_{t-1}$ highlights the behaviour of feedback traders that will impact the volatility of the Bitcoin market. We can see that the coefficient $\mu\left(\mathrm{VIX}_{t}\right)$ is $1-\gamma \mathrm{BTC}_{t-1}$, and it is a positive value since $\gamma \mathrm{BTC}_{t-1}=F_{t}^{d}<1$. Therefore, we can prove that VIX has a positive influence on BTC. High VIX indicates the surge in fear sentiment among market investors, such as the financial crisis or a war. Whenever financial crises, 
political turmoil and local wars break out, some people will start to think of ways to save their assets from damage, and storing Bitcoin has become the choice of some people. People can rely on holding Bitcoin to avoid property losses caused by high VIX, thereby achieving the purpose of asset hedging.

\section{Methodology}

\subsection{Bootstrap full-sample causality test}

When performing the Granger causality test of the traditional vector autoregressive (VAR) model, the variables have to follow the standard asymptotic distribution. Finally, to avoid result bias, we apply the residual bootstrap method $(R B)$ developed by Shukur and Mantalos (1997) to check our result robustness. The critical value may be more accurate than the asymptotic value to follow the standard asymptotic distribution. Furthermore, they investigate the power and size characteristics, proving that the likelihood ratio statistic can be corrected, even when the time series is small. They also propose the likelihood ratio $(L R)$ test, the result of which will be updated based on the features of power and size (Shukur \& Mantalos, 2000). Therefore, we investigate the interaction between VIX and BTC employing $R B$-based modified- $L R$ statistics in this paper.

We construct the bivariate $\operatorname{VAR}(p)$ process as follow:

$$
Y_{t}=\mu_{0}+\mu_{1} Y_{t-1}+\ldots \ldots+\mu_{p} Y_{t-p}+\varepsilon_{t} t=1,2, \ldots, T,
$$

where $p$ represents an optimal lag order determined by Schwarz Information Criterion (SIC). We can divide $Y$ the $\operatorname{VAR}(p)$ process into VIX and BTC, that is $Y_{t}=\left(\mathrm{VIX}_{t}, \mathrm{BTC}_{t}\right)^{\prime}$. Also, since the fluctuation in the US dollar index (USDX) can simultaneously affect BTC and VIX, it will impact the correlation in one pair of variables (Dyhrberg, 2016b; Zhu et al., 2017; Qin et al., 2020; Su et al., 2020b). Therefore, we choose USDX as the control variable in the VAR model, as shown in Equation (6) below:

$$
\left[\begin{array}{c}
\mathrm{VIX}_{t} \\
\mathrm{BTC}_{t}
\end{array}\right]=\left[\begin{array}{l}
\mu_{10} \\
\mu_{20}
\end{array}\right]+\left[\begin{array}{lll}
\mu_{11}(L) & \mu_{12}(L) & \mu_{13}(L) \\
\mu_{21}(L) & \mu_{22}(L) & \mu_{23}(L)
\end{array}\right]\left[\begin{array}{l}
\operatorname{VIX}_{t} \\
\operatorname{BTC}_{t} \\
\operatorname{USDX}_{t}
\end{array}\right]+\left[\begin{array}{c}
\varepsilon_{1 t} \\
\varepsilon_{2 t}
\end{array}\right] \text {, }
$$

where the white-noise process is shown as $\varepsilon_{t}=\left(\varepsilon_{1 t}, \varepsilon_{2 t}\right)^{\prime} . \mu_{i j}(L)=\sum_{k=1}^{p} \mu_{i j, k} L^{k}$, where $i=1,2$, $j=1,2,3$ and $L$ is a lag operator, defined as $L^{k} Y_{t}=Y_{t-k}$.

Based on Equation (6), the null hypothesis that BTC cannot affect VIX $\mu_{12, k}=0$ can be rejected when BTC will cause VIX to fluctuate. Similarly, the null hypothesis that VIX cannot influence BTC $\left(\mu_{21, k}=0\right)$ will also be examined.

\subsection{Parameter stability test}

One of the prerequisites for the above test is that the VAR system parameters are constant. Lucas (1976) once points out that although the model parameters can be statistically inferred under unstable conditions, they may obscure the true economic relationship and make the test results inaccurate. Hence, we conduct the parameter stability test containing the Sup-F, 
Ave-F, and Exp-F tests (Andrews, 1993; Andrews \& Ploberger, 1994), which could assess structural changes over the time trajectory. For the sake of verifying whether the parameters obey random walk processes, we also use the $L_{c}$ statistics test (Nyblom, 1989; Hansen, 1992). If the parameters are not stable, we can employ the above four tests to calculate the non-stable link between VIX and BTC. The sub-sample test should also be used to assess the association between the two variables (Su et al., 2021b).

\subsection{Bootstrap sub-sample rolling-window causality test}

Balcilar et al. (2010) develop a sub-sample test, which divides the entire sample into multiple small parts according to the rolling window width $r$. Let the time series length is $S$, and in each separated section final, there are $r, r+1, \ldots . ., S$, and $S-r+1$ sub-samples available. Each one can obtain the Granger causality result by summarizing the modified $L R$ statistics based on RB. The average of a significant number of estimations $N_{b}^{-1} \sum_{k=1}^{p} \hat{\mu}_{12, k}^{*}$ indicates the effect from BTC to VIX and $N_{b}^{-1} \sum_{k=1}^{p} \hat{\mu}_{21, k}^{*}$ suggests the influence from VIX to BTC, respectively. The number of bootstrap iterations is given by $N_{b} \cdot \hat{\mu}_{12, k}^{*}$ and $\hat{\mu}_{21, k}^{*}$ are the estimations through Equation (6). This paper applies a 90\% confidence interval, as well as the relevant lower ( $5^{\text {th }}$ quantile) and upper (95 ${ }^{\text {th }}$ quantile) limits (Balcilar et al., 2010; Su et al., 2021c).

\section{Data}

This study considers monthly data between 2010:M7 and 2020:M10 to investigate the causality between Bitcoin price and fear sentiment. On July 11, 2010, the technology media Slashdot has first reported on Bitcoin. Soon afterwards, the first Bitcoin exchange platform-MT. Gox has been found. It brings convenience for Bitcoin transactions, thus attracting a large number of investors at the beginning. We obtain data on Bitcoin price ${ }^{1}$, which is dominated by US dollars. The VIX index is compiled by using the implied volatility derived from the reverse deduction of the S\&P500 index option premium price and considering the method of interpolation to compile the volatility of buying put options and near and far months. Thereby, we can use the VIXindex to express the market fear sentiment (Whaley, 2000; Smales, 2014). Moreover, trade friction between China and the United States in 2018, in the context of deteriorating global business sentiment, caused VIX to soar nearly $50 \%$ from September to October. Then, investors chose to sell Bitcoin to hedge against this fear sentiment, causing the BTC to fall. We can consider that BTC fluctuations may depend on the market fear sentiment, that is, VIX. Next, we obtain VIX data from the Chicago Board Options Exchange (CBOE) to measure investors' sentiment. As a measure of uncertainty in the financial market, it is universally recognized by a large number of investors (Mele et al., 2015). When the VIX is higher, it means that the market participants expect that the market volatility will be more intense, and it also reflects the risk sentiment of investors and vice versa. Thereby, mutual relationships between BTC and VIX will affect investor sentiment, which in turn will change their investment strategy decisions. Thereby, mutual relationships between BTC and VIX can

\footnotetext{
$\overline{1}$ Bitcoin prices in US dollars are taken from Yahoo Finance.
} 
affect investors' decision-making about the distribution of portfolios and hedging strategies. Figure 1 shows the trends of VIX and BTC.

From Figure 1, we can notice that at the beginning, BTC does not increase even VIX is higher. In November 2013, when the Ukraine crisis has broken out, Russia, the European Union, the US, and several major powers fight over "geopolitics". The US and the European Union have imposed sanctions on Russia and banned exports that help strengthen military power, which causes a sharp deterioration in relations between the two countries. The tension between the two countries, especially in these influential countries (such as China, the United States, Russia and Japan), will cause public panic and impact on the financial market (Jiang et al., 2020; Qin et al., 2020; Su et al., 2020c). This crisis causes fear sentiment among financial markets, and international crude oil prices plummet (Panagiotidis et al., 2019). More investors take a fancy to Bitcoin's alternative to fiat currencies and investment potential, which pushes the rise of BTC. However, VIX has not changed much and remains at a relatively stable level. Since the Ukraine crisis is the US and European energy sanctions on Russia, the financial market impact is controllable and did not cause drastic fluctuations in the VIX. In August 2015, the Shanghai stock market plummeted, setting the highest drop since February 2007. It also affects major Asian and European stock markets, causing the US stock market to close with a sharp drop. The Dow Jones Industrial Average falls $3.58 \%$ in one day, and the VIX rises to 53.29. However, BTC has been at a low level. Hence, Bitcoin cannot hedge the risks of fear sentiment during this period. In 2016, the uncertainty brought by Brexit and the US election caused VIX to remain high. High partisan conflict may increase the U.S. economic policy uncertainty (Su et al., 2020d), which will help stimulate demand for Bitcoin to hedge risks. Subsequently, with the world's passionate investment in Bitcoin, BTC reaches its maximum value in 2017, more than 15 times in just one year. In 2018, as the Federal Reserve raises interest rates and the US dollar strengthens, the price of BTC drops sharply.

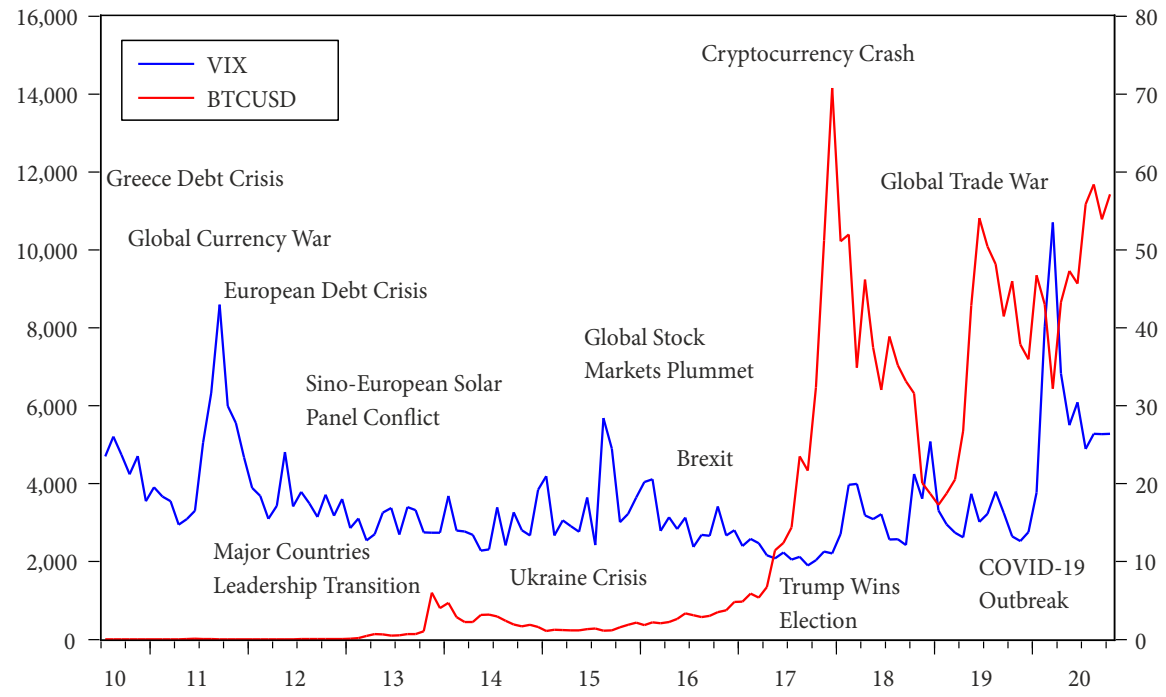

Figure 1. The trend of VIX and BTC 
At the same time, the increasing risks such as the strengthening of global regulations, hacking attacks, concerns about bubbles, and the withdrawal of major players eventually reduce investment (Su et al., 2021d), which lead to the collapse of cryptocurrencies. After the outbreak of the Sino-U.S. trade conflict, the price of BTC dropped again. At the same time, VIX fluctuates sharply as the conflict intensifies. The price of BTC has dropped by nearly $80 \%$ within a year, but on the contrary, it causes VIX to more than double. In 2019 , as the Sino-U.S. trade war continues to stalemate, global business sentiment has deteriorated, and the scope of the trade battle has gradually expanded. It includes US auto tariffs, trade disputes between Europe and the US, the U.S.-Mexico-Canada agreement, and the tense trade frictions between Japan and South Korea. The global trade war uncertainty has caused VIX to fluctuate continuously, but BTC has begun a second round of skyrocketing. In 2020, a sudden COVID-19 swept the world, bringing huge economic and political shocks to all countries. VIX has skyrocketed by more than $50 \%$ in one month. Affected by factors such as the epidemic and the oil plunge, the three major U.S. stock indexes have fallen. The liquidity risk under the downward pressure of the economy makes people more inclined to use high liquid assets such as cash and gold, and BTC has dropped from over \$10,000 in February to under $\$ 4,000$ in March. In short, the interaction between BTC and VIX is complex and changeable.

Additionally, VIX may impact the dollar, and Bitcoin is priced by it, which will affect BTC. VIX may affect the US dollar trend, and Bitcoin is priced by it, which in turn affects BTC. Thereby, the BTC fluctuations may be influenced by the dollar, and the depreciation of the US dollar will bring about the rise in BTC, and vice versa. Since the correlation between VIX and BTC can be affected by the US dollar index (USDX) ${ }^{2}$, we consider it a control variable. As shown in Table 1.

The mean of VIX, BTC, and USDX is 17.809, 2765.951, and 89.268, respectively. Skewness is positive for VIX and BTC, except for USDX, indicating asymmetry. The kurtosis parameter value is greater than 3 , which means VIX with the feature of leptokurtic distribution ${ }^{3}$,

Table 1. Descriptive statistics

\begin{tabular}{|l|c|c|c|}
\hline & VIX & BTC & USDX \\
\hline Observations & 124 & 124 & 124 \\
\hline Mean & 17.809 & 2765.951 & 89.268 \\
\hline Median & 16.105 & 465.049 & 92.935 \\
\hline Maximum & 53.540 & 14156.41 & 102.390 \\
\hline Minimum & 9.510 & 0.060 & 72.930 \\
\hline Standard Deviation & 6.757 & 3848.008 & 8.518 \\
\hline Skewness & 2.219 & 1.172 & -0.281 \\
\hline Kurtosis & 10.015 & 2.889 & 1.510 \\
\hline Jarque-Bera & $356.074^{* * *}$ & $28.447^{* * *}$ & $13.102^{* * *}$ \\
\hline
\end{tabular}

Note: ${ }^{* *}$ denotes significance at $1 \%$ level.

\footnotetext{
2 The USDX index comes from Yahoo Finance.

3 The leptokurtic distribution can be described as having a wider or flatter shape with fatter tails resulting in a greater chance of extreme positive or negative events. The opposite is a platykurtic distribution.
} 
showing a greater probability of extreme events. Simultaneously, the Jarque-Bera test results strongly reject the normality hypothesis at the $1 \%$ level. Therefore, instead of the traditional Granger causality test, we will apply the bootstrap sub-sample rolling window method to explore the Granger causality between VIX and BTC over time. We can take the natural logarithm of VIX, BTC, and USDX to avoid potential heteroscedasticity in the parameters (Su et al., 2020e).

\section{Empirical results}

We consider the bivariate VAR model constructed by VIX and BTC to measure all samples of causality according to Equation (6). Based on the Schwarz information criterion (SIC), we select the optimal lag length as 2 . Table 2 presents the results of the full-sample bootstrap Granger causality test. The $p$-values reveal that the interaction between VIX and BTC is insignificant, which indicates that VIX cannot cause BTC and vice versa. The results are contradictory to existing studies (Kristoufek, 2015; Bouri et al., 2017b; Al-Yahyaee et al., 2019) and the ICAPM deduction, which underlines that VIX may be beneficial to BTC.

In the above bivariate VAR model with VIX and BTC, the full-sample test assumes that the parameters are stable over time. Nevertheless, due to the VAR model's structural changes, the causal link between BTC and VIX may exhibit the time-varying characteristic (Balcilar \& Ozdemir, 2013). Following Andrews (1993) and Andrews and Ploberger (1994), the instability of the two parameters of VIX and BTC can be detected by Sup-F, Ave-F, and Exp-F tests. Also, the $L_{c}$ statistics test (Nyblom, 1989; Hansen, 1992) further improves the reliability of Granger causality tests. The results of the above tests are shown in Table 3.

Sup- $F$ test shows that VIX, BTC, and the VAR system have structural changes at a $1 \%$ significance level. We can find that BTC and VAR system show sudden structural changes

Table 2. Full-sample Granger causality tests

\begin{tabular}{|c|c|c|c|c|}
\hline \multirow{2}{*}{ Tests } & \multicolumn{2}{|c|}{$\mathrm{H}_{0}$ : VIX does not Granger cause BTC } & \multicolumn{2}{c|}{$\mathrm{H}_{0}$ : BTC does not Granger cause VIX } \\
\cline { 2 - 5 } & Statistics & $p$-values & Statistics & $p$-values \\
\hline Bootstrap $L R$ test & 2.175 & 0.118 & 2.251 & 0.110 \\
\hline
\end{tabular}

Notes: This study uses 10,000 bootstrap repetitions to calculate $p$-values.

Table 3. Parameter stability test

\begin{tabular}{|l|c|c|c|c|c|c|}
\hline \multirow{2}{*}{ Tests } & \multicolumn{2}{|c|}{ VIX } & \multicolumn{2}{c|}{ BTC } & \multicolumn{2}{c|}{ VAR system } \\
\cline { 2 - 7 } & Statistics & $p$-value & Statistics & $p$-value & Statistics & $p$-value \\
\hline Sup-F & $21.764^{* * *}$ & 0.002 & $37.452^{* * *}$ & 0.000 & $32.607^{* * *}$ & 0.000 \\
\hline Ave-F & $7.406^{* *}$ & 0.019 & $13.466^{* *}$ & 0.000 & $24.086^{* * *}$ & 0.000 \\
\hline Exp-F & $7.256^{* * *}$ & 0.004 & $14.330^{* * *}$ & 0.000 & $14.052^{* * *}$ & 0.000 \\
\hline$L_{c}$ & & & & & $5.456^{* *}$ & 0.005 \\
\hline
\end{tabular}

Notes: This study uses 10,000 bootstrap repetitions to calculate $p$-values. ${ }^{* *}$ and ${ }^{* *}$ denote significance at 1 and 5 percent, respectively. 
at the $1 \%$ level through the Ave-F test, while 5\% significance level for VIX. The Exp-F test reveals the parameters in variables will progressively change as time goes on in VIX, BTC, and VAR systems. The $L_{c}$ statistic test shows that the random walk process cannot be realized in the VAR model while at a $1 \%$ level, which further demonstrates the time-varying nature of the model variables. Therefore, according to the stability test, we find a significant non-constant interaction between VIX and BTC, so the results of the full-sample test are unreliable in the study. Consequently, to determine the time variations interaction between VIX and BTC, we conduct the bootstrap sub-sample rolling-window causality test (Su et al., 2020e). In particular, the rolling window width is selected as $24^{4}$ to ensure the credibility of causality analysis in this paper.

According to the $p$-values in Figure 2, we can identify the degree and direction of the impact of VIX on BTC. VIX Granger causes BTC in the periods of 2014:M01-2014:M03 and 2019:M03-2019:M04 at the 10\% significance level and has a significant negative impact on BTC.

The negative effects can evidence that Bitcoin does not appear to be a safe haven in fear sentiment. Since the negative effects of fear sentiment caused by geopolitical events (e.g., the Syrian crisis and Ukraine conflicts), VIX increases during 2014:M01-2014:M03. The impact mechanism of VIX on BTC can be explained from the following two aspects. First, VIX, which usually represents the degree of market risk expectations in the future, has risen, indicating an increase in market fear sentiment. Investors will choose to invest in hedging assets to avoid losses (Su et al., 2020c), such as gold, so this will cause gold prices to fluctuate and rise in the first three months of 2014. However, Bitcoin, as an emerging market, has extremely high average returns and volatility (Bouri et al., 2018a), making it more of a speculative tool. Under the panic, the demand for risky assets will decrease, and the price of Bitcoin has fallen. Second, concerns about the security of Bitcoin can also lead to a decrease in demand (Mauro et al., 2018; Zaghloul et al., 2019). The frequent theft of cryptocurrency exchange platforms (e.g., Mt.Gox, which hackers have repeatedly attacked, finally declared bankruptcy due to the massive theft of Bitcoin) causes investors to worry about the security of the Bitcoin market, which results in the escape of a great number of investors from the Bitcoin market (Bradbury, 2015). Several governments have also imposed restrictions on Bitcoin transactions (e.g., The European Banking Authority (EBA) prohibits EU banks from buying, holding, and selling virtual currencies, including Bitcoin). That will dampen the enthusiasm for Bitcoin investment, which leads to a downward trend in BTC.

In conclusion, the inherent hedging properties of Bitcoin have not yet been fully noticed, so BTC will not change significantly with VIX. Therefore, even if VIX is on the rise, BTC is still at a low level. Accordingly, the negative impact of VIX on BTC during the period of 2014:M01-2014:M03 can be proved.

In 2019, the global trade war (e.g., US President Trump's auto tariffs, trade disputes between Europe and the US, the U.S.-Mexico-Canada agreement, and fierce trade frictions between Japan and South Korea) continued to loom. With the Sino-U.S. business negotiations, the fear sentiment caused by the trade war has eased, VIX maintains at a low level. The rise

\footnotetext{
${ }^{4}$ We change the rolling-window widths of 20-, 28- and 32- months, respectively. These outcomes are similar to 24-months rolling-window.
} 

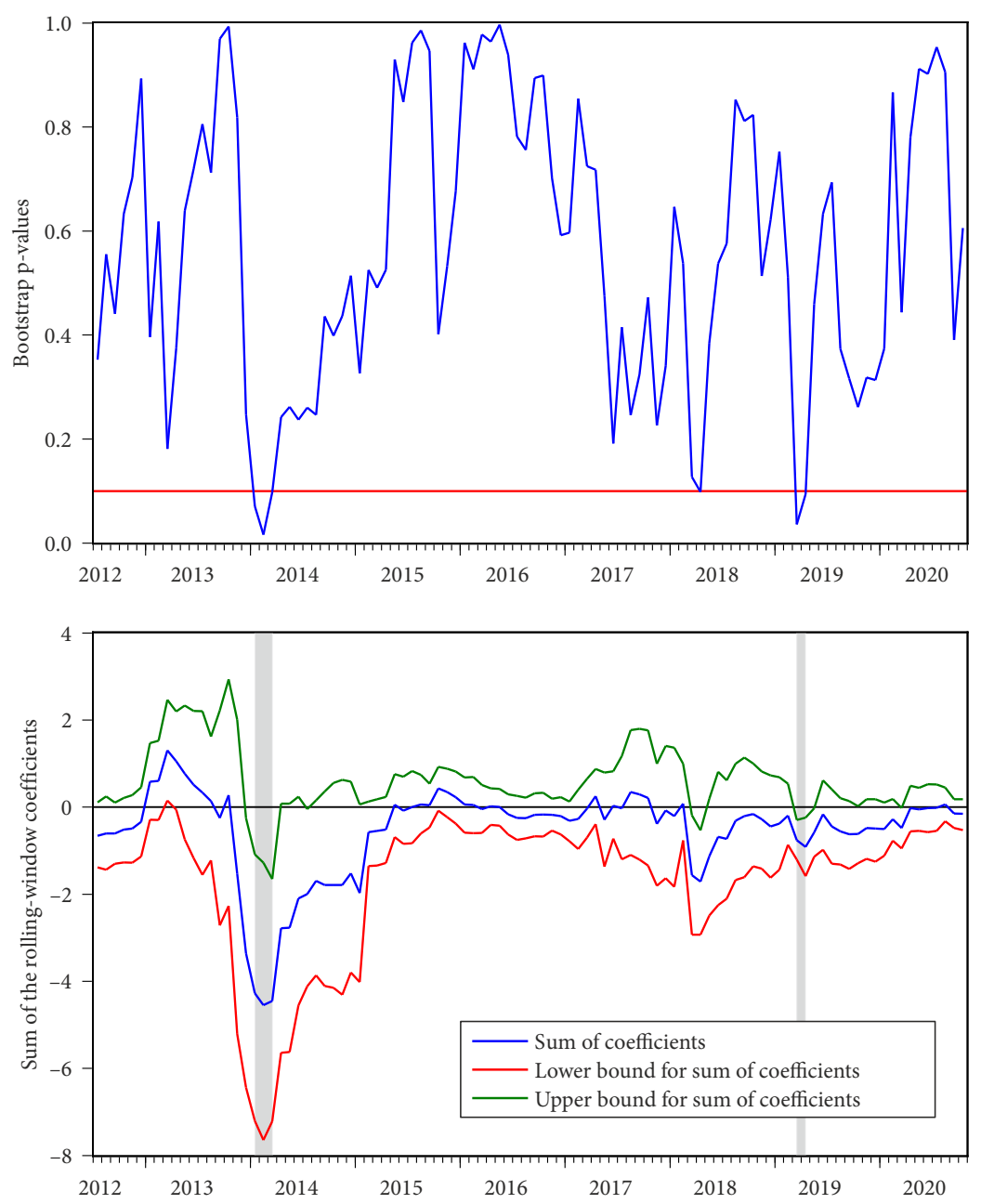

Figure 2. Impact of VIX on BTC

of BTC can be explained by avoiding the spread of fear sentiment caused by political events. The Trump administration's trade policy triggered one of the largest trade wars of contemporary global trade. Since 2018, the United States has imposed import tariffs on more than 280 billion U.S. dollars of goods, of which more than 120 billion U.S. dollars in tariffs have been imposed on China ${ }^{5}$. The scope of the U.S. - China trade war has gradually expanded to the entire global economy. This situation has caused investors to panic and began to turn to assets such as gold and cryptocurrencies to hedge trade uncertainty (Plakandaras et al., 2021). This will stimulate Bitcoin investment and lead to the rise of Bitcoin (Ciaian et al., 2016; Su et al., 2019a; Qin et al., 2020).

\footnotetext{
5 The Trump administration subsequently extended the scope of the trade war to Canada, the European Union, and Russia. Countries have also quickly responded to the United States. Canada imposed tariffs on US $\$ 12.8$ billion worth of US products, the European Union imposed additional tariffs on US\$7.2 billion US products, and Russia slammed back and imposed tariffs of $25-40 \%$ on imported US products.
} 
Meanwhile, the Trump administration's ambiguities in policies and the Federal Reserve's expectations of lower interest rates will lead to a reduction in investors' willingness to hold US dollars and drive demand for o Bitcoin. Also, the Middle East geopolitical structure, which is an important oil and gas resource-producing area, is far from complete. Repeated competition between all parties (e.g., the severance of diplomatic relations between Qatar and the four Gulf countries) has increased geopolitical risks in the Middle East, which has increased the uncertainty of the international oil price trend (Su et al., 2019a). The higher global energy costs have raised the break-even point of mining, which reduces the supply of Bitcoin (Das \& Dutta, 2020), and it will put higher demands on the price of Bitcoin (Huhtinen, 2014). Hence, we can conclude that VIX can negatively impact BTC during the period of 2019:M03-2019:M04. The negative effects of the above two periods are contrary to the results of ICAPM.

Figure 3 shows that the null hypothesis BTC has no Granger cause on VIX can be accepted, except 2014:M4-2014:M11, 2016:M6-2016:M7 and 2020:M9-2020:M10 when 10\% level. The influences are all positive; these indicate the indicative influence from BTC to VIX in a specific time period. February 2014 is a time period in which the closure of Mentougou has caused a severe decline in Bitcoin price, from a peak of US\$951.39 to US\$309.87, a drop of $67 \%$. Technological innovation will interfere with financial markets (Tao et al., 2021). Besides, the Group of Seven (G7 $)^{6}$ plans to strengthen digital currencies such as Bitcoin. The Central Bank of China has also imposed stricter supervision on digital currencies represented by Bitcoin. These regulatory policies cause BTC to plummet by $92.5 \%$ in 83 days and then rise again in May and June, but it could not stop the decline in the next 5 months. Security issues and the uncertainty of global encryption policies have led to a decrease in Bitcoin and BTC demand to fall during 2014:M4-2014:M11. Since Bitcoin as a safe-haven currency has not received much attention in 2014, investor sentiment fluctuations are not significant and relatively low.

Additionally to a slight rebound in July, VIX is also in a downward trend as a whole, which the Bitcoin market may also reflect. The European Central Bank's promotion of negative interest rates and the halving of international oil prices led to an increase in VIX, and at the same time, the price of BTC also increased. That means that VIX and BTC are in the same direction. Hence, Bitcoin can be a good predictor of the market fear sentiment. In conclusion, the positive impact from BTC to VIX during the period of 2014:M4-2014:M11 can be evidenced.

On June 24, 2016, the Brexit black swan event caused a fierce global financial market reaction. The pound exchange rate has collapsed in a flash and the rising fear sentiment in the market. Risk aversion in the market rises, and investors turn to safe-haven currencies such as the US dollar and gold to avoid risks. Bitcoin shows a certain degree of resilience in times of stress, showing potential hedging capabilities (Bouri \& Gupta, 2021). Since Bitcoin is considered to effectively reduce the risk in the investment portfolio (Dyhrberg, 2016b; Guesmi et al., 2019), it has brought widespread attention to the digital currency market (Glaser et al., 2014). To hedge VIX risks, the demand for Bitcoin has expanded, which also prompts BTC

\footnotetext{
${ }^{6}$ The Group of Seven (G7) is an organization made up of wealthy democracies consisting of Canada, France, Germany, Italy, Japan, the United Kingdom and the United States.
} 

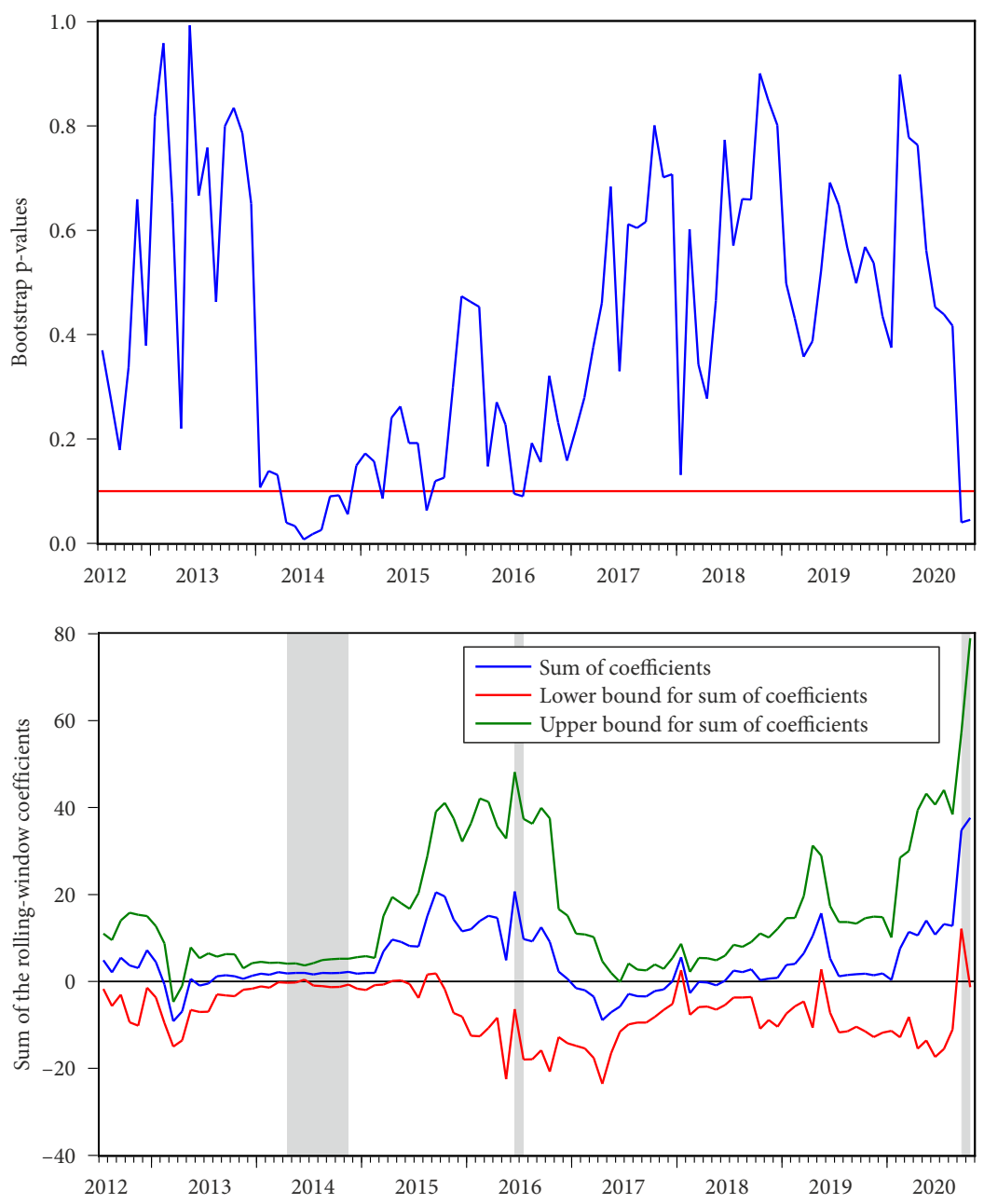

Figure 3. Impact of BTC on VIX

to increase. Subsequently, the Bank of England and the European Central Bank will adopt greater monetary easing policies to reduce the Brexit impact. The market generally believes that the US will not raise interest rates and may even cut interest rates. The depreciation of the dollar will increase the demand for Bitcoin and the rise of BTC. Deutsche Bank's failure to pass the stress test triggered market concerns about instability in the banking system. In an environment of high uncertainty and low trust, investors tend to stay away from major state-owned economies and often turn to Bitcoin (Bouri et al., 2018b). Therefore, the price of Bitcoin has soared and gained greater development. Investors regard Bitcoin as a sanctuary for the uncertainty of the traditional economy and banking system, which has promoted the further rise of Bitcoin. Hence, we can prove that BTC and VIX move in the same direction during the period of 2016:M6-2016:M7. The result evidence that Bitcoin can be considered as a safe haven in risk sentiment. 
In 2020:M9-2020:M10, there is a positive effect from BTC to VIX; the growth of BTC will correspond to the rise of VIX. There are two reasons behind the rise in BTC in this period. First, affected by COVID-19, the Gross Domestic Product (GDP) of countries has plummeted in the second quarter(e.g., the US has announced that the GDP plummeted $31.4 \%$ in the second quarter). In response to economic uncertainty, Bitcoin can be included in the asset portfolio as a tool for confronting downside risks. On the one hand, the US election outcome's uncertainty has also increased the demand for hedging currencies (such as Bitcoin). Because the two candidates' economic stances are very different, the investment environment has become uncertain. During this period, the global economic weakness has made trade frictions more intense; the US puts many Chinese companies on the sanctions list, causing further deterioration in Sino-U.S. relations. Increasing political risks and uncertainty in the investment environment will seriously impact global trade and economic development and deeply affect the dollar demand and influence. Market fear sentiment rises, and VIX has also increased. Also, the US has become the most deaths from the COVID-19 in the world. With the advent of winter, worries about the second wave of COVID-19 will also increase VIX. Therefore, the positive impact from BTC to VIX during the period can be evidenced, suggesting that the Bitcoin market can act as an effective tool when assessing the market fear sentiment.

\section{Conclusions}

This paper discusses whether Bitcoin should be regarded as a safe haven in fear sentiment by evaluating the causal interaction between VIX and BTC. Although the full-sample causality test results indicate that no apparent correlation can be found, this result is not credible because the parameter instability is not considered. The parameter stability tests reveal that the causal link between variables has sudden structural change and exhibits time variations. Thereby, we consider the bootstrap sub-sample rolling-window causality test to solve the time-varying problem between VIX and BTC. The main conclusion is that VIX is an important factor in BTC and has a negative impact. We can conclude that Bitcoin does not act as a safe asset in fear sentiment, which will help investors pursue maximum risk returns, especially in portfolio diversification and hedging strategies. The above results are unsupported by ICAPM, which ascertains that high VIX will stimulate the growth of BTC. In turn, the positive effect of BTC on VIX can evidence that the Bitcoin market can be a warning sign to predict investor's fear sentiment. In short, the transmission mechanism between the VIX and BTC concludes that Bitcoin cannot act as a safe haven in fear sentiment.

Although cryptocurrencies are often included in potential safe harbour investment, the empirical test of Bitcoin's safe harbour characteristics lacks the core element, which is fear sentiment in market downside risks. Clarifying the role of sentiment on Bitcoin demand and the interrelationship between BTC and VIX can provide investors and the government with reference. Firstly, VIX has a certain negative impact on BTC in a certain period of time. Therefore, based on the changes in VIX, investors can more accurately grasp the trend of BTC and rationally allocate the investment amount. If panic sentiment declines, then investors can consider including the Bitcoin ratio into their investment portfolio to increase 
investment returns. At the same time, the government can also strictly monitor the price fluctuations of Bitcoin based on VIX and take measures to avoid violent BTC fluctuations and cause market panic, which will damage public investment confidence. Secondly, due to the bursting of the Bitcoin bubble, investors should consider exiting the Bitcoin market and turning to safer assets (such as gold) with higher liquidity in the face of rising fear sentiment The technological innovations have resulted in many disruptions in the financial services industry, relevant departments should strengthen the supervision to prevent the crisis brought by Bitcoin from plummeting, and create a stable investment environment. On the other hand, an increase in BTC may cause VIX to rise at the same time. This shows that the government can view the Bitcoin market as a key factor in measuring market fears. The government can take measures to reduce the negative impact of emotions and control the crash caused by panic selling, which is fatal to the financial market. Given the increasing importance of Bitcoin, the government should also formulate relevant laws to regulate the trading market. At the same time, the development of encryption technology will help solve security issues, avoid further increases in the panic caused by overheating of Bitcoin, and promote the orderly development of the cryptocurrency market. In future researches, we will explore which asset (gold, Bitcoin or dollar) or portfolio has the best hedging ability.

\section{Funding}

This research is partly supported by the National Social Science Fund of China (20BJY021).

\section{References}

Al Mamun, M., Uddin, G. S., Suleman, M. T., \& Kang, S. H. (2020). Geopolitical risk, uncertainty and Bitcoin investment. Physica A: Statistical Mechanics and its Applications, 540, 123107. https://doi.org/10.1016/j.physa.2019.123107

Al-Yahyaee, K. H., Mensi, W., Al-Jarrah, I. M. W., Hamdi, A., \& Kang, S. H. (2019). Volatility forecasting, downside risk, and diversification benefits of Bitcoin and oil and international commodity markets: A comparative analysis with yellow metal. The North American Journal of Economics and Finance, 49, 104-120. https://doi.org/10.1016/j.najef.2019.04.001

Ali, M., Alam, N., \& Rizvi, S. A. R. (2020). Coronavirus (COVID-19) - An epidemic or pandemic for financial markets. Journal of Behavioral and Experimental Finance, 27, 100341. https://doi.org/10.1016/j.jbef.2020.100341

Andrews, D. W. K. (1993). Tests for parameter instability and structural change with unknown change point. Econometrica: Journal of the Econometric Society, 61(4), 821-856. https://doi.org/10.2307/2951764

Andrews, D. W. K., \& Ploberger, W. (1994). Optimal tests when a nuisance parameter is present only under the alternative. Econometrica: Journal of the Econometric Society, 62(6), 1383-1414. https://doi.org/10.2307/2951753

Atsalakis, G. S., Atsalaki, I. G., Pasiouras, F., \& Zopounidis, C. (2019). Bitcoin price forecasting with neuro-fuzzy techniques. European Journal of Operational Research, 276(2), 770-780. https://doi.org/10.1016/j.ejor.2019.01.040

Baek, C., \& Elbeck, M. (2015). Bitcoins as an investment or speculative vehicle? A first look. Applied Economics Letters, 22(1), 30-34. https://doi.org/10.1080/13504851.2014.916379 
Balcilar, M., Ozdemir, Z. A., \& Arslanturk, Y. (2010). Economic growth and energy consumption causal nexus viewed through a bootstrap rolling window. Energy Economics, 32(6), 1398-1410.

Balcilar, M., \& Ozdemir, Z. A. (2013). The export-output growth nexus in Japan: A bootstrap rolling window approach. Empirical Economics, 44, 639-660. https://doi.org/10.1007/s00181-012-0562-8

Balcilar, M., Bouri, E., Gupta, R., \& Roubaud, D. (2017). Can volume predict Bitcoin returns and volatility? A quantiles-based approach. Economic Modelling, 64, 74-81.

https://doi.org/10.1016/j.econmod.2017.03.019

Baur, D. G., Hong, K., \& Lee, A. D. (2018). Bitcoin: medium of exchange or speculative assets. Journal of International Financial Market, Institutions and Money, 54, 177-189. https://doi.org/10.1016/j.intfin.2017.12.004

Baur, D. G., \& Lucey, B. M. (2010). Is gold a hedge or a safe haven? An analysis of stocks, bonds and gold. Financial Review, 45, 217-229. https://doi.org/10.1111/j.1540-6288.2010.00244.x

Black, F. (1986). Noise. The Journal of Finance, 41, 529-543. https://doi.org/10.1111/j.1540-6261.1986.tb04513.x

Bollen, J., Mao, H., \& Zeng, X. (2011). Twitter mood predicts the stock market. Journal of Computational Science, 2(1), 1-8. https://doi.org/10.1016/j.jocs.2010.12.007

Bouoiyour, J., Selmi, R., \& Wohar, M. E. (2019). Safe havens in the face of presidential election uncertainty: A comparison between Bitcoin, oil and precious metals. Applied Economics, 51(57), 60766088. https://doi.org/10.1080/00036846.2019.1645289

Bouri, E., Gkillas, K., \& Gupta, R. (2019). Trade uncertainties and the hedging abilities of Bitcoin. Economic Notes, 49(3), e12173. https://doi.org/10.1111/ecno.12173

Bouri, E., \& Gupta, R. (2021). Predicting Bitcoin returns: Comparing the roles of newspaper- and internet search-based measures of uncertainty. Finance Research Letters, 38, 101398. https://doi.org/10.1016/j.frl.2019.101398

Bouri, E., Gupta, R., Lahiani, A., \& Shahbaz, M. (2018a). Testing for asymmetric nonlinear short and long-run relationships between bitcoin, aggregate commodity and gold prices. Resources Policy, 57, 224-235. https://doi.org/10.1016/j.resourpol.2018.03.008

Bouri, E., Gupta, R., Lau, C. K. M., Roubaud, D., \& Wang, S. (2018b). Bitcoin and global financial stress: a copula-based approach to dependence and causality in quantiles. The Quarterly Review of Economics and Finance, 69, 297-307. https://doi.org/10.1016/j.qref.2018.04.003

Bouri, E., Molnár, P., Azzi, G., Roubaud, D., \& Hagfors, L. I. (2017a). On the hedge and safe haven properties of Bitcoin: Is it really more than a diversifier. Finance Research Letters, 20, 192-198. https://doi.org/10.1016/j.frl.2016.09.025

Bouri, E., Azzi, G., \& Dyhrberg, A. H. (2017b). On the return-volatility relationship in the Bitcoin market around the price crash of 2013. Economics, 11(2), 1-17.

https://doi.org/10.5018/economics-ejournal.ja.2017-2

Bouri, E., Jalkh, N., Molnár, P., \& Roubaud, D. (2017c). Bitcoin for energy commodities before and after the December 2013 crash: Diversififier, hedge or safe haven? Applied Economics, 49(50), 5063-5073. https://doi.org/10.1080/00036846.2017.1299102

Bouri, E., Gupta, R., Tiwari, A. K., \& Roubaud, D. (2017d). Does Bitcoin hedge global uncertainty? Evidence from wavelet-based quantile-in-quantile regressions. Finance Research Letters, 23, 87-95. https://doi.org/10.1016/j.frl.2017.02.009

Bradbury, D. (2015). In blocks we trust [Bitcoin security]. Engineering \& Technology, 10(2), 68-71. https://doi.org/10.1049/et.2015.0208

Brière, M., Oosterlinck, K., \& Szafarz, A. (2015). Virtual currency, tangible return: portfolio diversification with bitcoin. Journal of Asset Management, 16, 365-373. https://doi.org/10.1057/jam.2015.5

Bukovina, J., \& Martiček, M. (2016). Sentiment and Bitcoin volatility (MENDELU Working Papers in Business and Economics No. 58/2016). Mendel University in Brno, Faculty of Business and Economics http://ftp.mendelu.cz/RePEc/men/wpaper/58_2016.pdf 
Celeste, V., Corbet, S., \& Gurdgiev, C. (2018, August). Fractal dynamics and wavelet analysis: Deep volatility properties of Bitcoin, ethereum and ripple (Working Paper). https://doi.org/10.2139/ssrn.3232913

Chan, W. H., Le, M., \& Wu, Y. W. (2019). Holding bitcoin longer: The dynamic hedging abilities of Bitcoin. The Quarterly Review of Economics and Finance, 71, 107-113. https://doi.org/10.1016/j.qref.2018.07.004

Cheah, E. T., \& Fry, J. (2015). Speculative bubbles in bitcoin markets? An empirical investigation into the fundamental value of bitcoin. Economics Letters, 130, 32-36. https://doi.org/10.1016/j.econlet.2015.02.029

Chen, C., Liu, L., \& Zhao, N. (2020). Fear sentiment, uncertainty, and Bitcoin price dynamics: The case of COVID-19. Emerging Markets Finance and Trade, 56(10), 2298-2309. https://doi.org/10.1080/1540496X.2020.1787150

Ciaian, P., Rajcaniova, M., \& Kancs, D. (2016). The economics of Bitcoin price formation. Applied Economics, 48(19), 1799-1815. https://doi.org/10.1080/00036846.2015.1109038

Ciner, C., Gurdgiev, C., \& Lucey, B. M. (2013). Hedges and safe haves: An examination of stocks, bonds, gold, oil and exchange rates. International Review of Financial Analysis, 29, 202-211. https://doi.org/10.1016/j.irfa.2012.12.001

Conlon, T., \& McGee, R. (2020). Safe haven or risky hazard? Bitcoin during the Covid-19 bear market. Finance Research Letters, 35, 101607. https://doi.org/10.1016/j.frl.2020.101607

Das, D., \& Dutta, A. (2020). Bitcoin's energy consumption: Is it the Achilles Heel to miner's revenue. Economics Letters, 186, 108530. https://doi.org/10.1016/j.econlet.2019.108530

Dastgir, S., Demir, E., Downing, G., Gozgor, G., \& Lau, C. K. M. (2019). The causal relationship between Bitcoin attention and Bitcoin returns: Evidence from the copula-based Granger causality test. Finance Research Letters, 28, 160-164. https://doi.org/10.1016/j.frl.2018.04.019

Da, Z., Engelberg, J., \& Gao, P. (2015). The sum of all fears investor sentiment and asset prices. The Review of Financial Studies, 28(1), 1-32. https://doi.org/10.1093/rfs/hhu072

Demir, E., Gozgor, G., Lau, C. K. M., \& Vigne, S. A. (2018). Does economic policy uncertainty predict the Bitcoin returns? An empirical investigation. Finance Research Letters, 26, 145-149. https://doi.org/10.1016/j.frl.2018.01.005

Dyhrberg, A. H. (2016a). Bitcoin, gold and the dollar - A GARCH volatility analysis. Finance Research Letters, 16, 85-92. https://doi.org/10.1016/j.frl.2015.10.008

Dyhrberg, A. H. (2016b). Hedging capabilities of bitcoin. Is it the virtual gold. Finance Research Letters, 16, 139-144. https://doi.org/10.1016/j.frl.2015.10.025

El Alaoui, M., Bouri, E., \& Roubaud, D. (2019). Bitcoin price-volume: A multifractal cross-correlation approach. Finance Research Letters, 31. https://doi.org/10.1016/j.frl.2018.12.011

Georgoula, I., Pournarakis, D., Bilanakos, C., Sotiropoulos, D., \& Giaglis, G. M. (2015). Using time-series and sentiment analysis to detect the determinants of Bitcoin prices. https://doi.org/10.2139/ssrn.2607167

Glaser, F., Haferkorn, M., Weber, M. C., \& Zimmermann, K. (2014). How to price a digital currency? Empirical insights on the influence of media coverage on the Bitcoin bubble. MKWI 2014 (Paderborn) \& Banking and Information Technology, 15(1). https://ssrn.com/abstract=2430653

Guesmi, K., Saadi, S., Abid, I., \& Ftiti, Z. (2019). Portfolio diversification with virtual currency: Evidence from bitcoin. International Review of Financial Analysis, 63, 431-437. https://doi.org/10.1016/j.irfa.2018.03.004

Guo, K., Sun, Y., \& Qian, X. (2017). Can investor sentiment be used to predict the stock price? Dynamic analysis based on China stock market. Physica A: Statistical Mechanics and its Applications, 469, 390-396. https://doi.org/10.1016/j.physa.2016.11.114 
Hansen, B. E. (1992). Tests for parameter instability in regressions with I(1) processes. Journal of Business \& Economic Statistics, 20(1), 45-59. https://doi.org/10.1198/073500102753410381

Harvey, C. R. (2014). Bitcoin myths and facts. National Bureau of Economic Research. https://doi.org/10.2139/ssrn.2479670

Huhtinen, T.-P. (2014). Bitcoin as a monetary system: Examining attention and attendance [Master's thesis]. Aalto University School of Business. https://core.ac.uk/download/pdf/80712618.pdf

Jareño, F., González, M. O., Tolentino, M., \& Sierra, K. (2020). Bitcoin and gold price returns: A quantile regression and NARDL analysis. Resources Policy, 67, 101666. https://doi.org/10.1016/j.resourpol.2020.101666

Jiang, Y., Ren, Y. S., Ma, C. Q., Liu, J. L., \& Sharp, B. (2020). Does the price of strategic commodities respond to U.S. partisan conflict? Resources Policy, 66, 101617. https://doi.org/10.1016/j.resourpol.2020.101617

Jubinski, D., \& Lipton, A. F. (2012). Equity volatility, bond yields, and yield spreads. Journal of Futures Market, 32(5), 480-503. https://doi.org/10.1002/fut.20521

Karalevicius, V., Degrande, N., \& De Weerdt, J. (2018). Using sentiment analysis to predict interday Bitcoin price movements. Journal Risk Finance, 19(1), 56-75. https://doi.org/10.1108/JRF-06-2017-0092

Keynes, J. M. (1936). The general theory of employment, interest and money. Palgrave MacMillan.

Kharpal, A. (2017). Central banks could hold bitcoin and ether for the first time in 2018, cryptocurrency CEO says. https://www.cnbc.com/2017/12/18/central-banks-will-hold-bitcoin-and-ether-in2018-blockchain-ceo.html

Kindleberger, C. P. (1978). Manias, panics and crashes: A history of financial crises. Palgrave Macmillan.

Kjærland, F., Khazal, A., Krogstad, E. A., Nordstrøm, F. B. G., \& Oust, A. (2018). An analysis of Bitcoin's price dynamics. Journal of Risk and Financial Management, 11(4), 1-18. https://doi.org/10.3390/jrfm11040063

Kristoufek, L. (2013). Fractal markets hypothesis and the global financial crisis: Wavelet power evidence. Scientific Reports, 3, 2857. https://doi.org/10.1038/srep02857

Kristoufek, L. (2015). What are the main drivers of the bitcoin price? Evidence from wavelet coherence analysis? Plos One, 10(4), 1-14. https://doi.org/10.1371/journal.pone.0123923

López-Cabarcos, M. Á., Pérez-Pico, A. M., Piñeiro-Chousa, J., \& Šević, A. (2021). Bitcoin volatility, stock market and investor sentiment. Are they connected. Finance Research Letters, 38, 101399. https://doi.org/10.1016/j.frl.2019.101399

Lucas, R. E. (1976). Econometric policy evaluation: A critique. Carnegie-Rochester Conferences Series on Public Policy, 1, 19-46. https://doi.org/10.1016/S0167-2231(76)80003-6

Matkovskyy, R., \& Jalan, A. (2019). From financial markets to Bitcoin markets: A fresh look at the contagion effect. Finance Research Letters, 31, 93-97. https://doi.org/10.1016/j.frl.2019.04.007

Mauro, C., Kumar, E. S., Chhagan, L., \& Sushmita, R. (2018). A survey on security and privacy issues of Bitcoin. IEEE Communications Surveys \& Tutorials, 20(4), 3416-3452. https://doi.org/10.1109/COMST.2018.2842460

Mele, A., Obayashi, Y., \& Shalen, C. (2015). Rate fears gauges and the dynamics of fixed income and equity volatilities. Journal of Banking \& Finance, 52, 256-265.

https://doi.org/10.1016/j.jbankfin.2014.04.030

Merton, R. C. (1973). An intertemporal capital asset pricing model. Econometrica, 41(5), 867-887. https://doi.org/10.2307/1913811

Nakamoto, S. (2008). Bitcoin: A peer-to-peer electronic cash system. https://ssrn.com/abstract=3440802

Nofsinger, J. (2005). Social mood and financial economics. The Journal of Behavioral Finance, 6(3), 144-160. https://doi.org/10.1207/s15427579jpfm0603_4 
Nyblom, J. (1989). Testing for the constancy of parameters over time. Journal of the American Statistical Association, 84(405), 223-230. https://doi.org/10.1080/01621459.1989.10478759

Panagiotidis, T., Stengos, T., \& Vravosinos, O. (2019). The effects of markets, uncertainty and search intensity on Bitcoin returns. International Review of Financial Analysis, 63, 220-242. https://doi.org/10.1016/j.irfa.2018.11.002

Philippas, D., Rjiba, H., Guesmi, K., \& Goutte, S. (2019). Media attention and Bitcoin prices. Finance Research Letters, 30, 37-43. https://doi.org/10.1016/j.frl.2019.03.031

Plakandaras, V., Bouri, E., \& Gupta, R. (2021). Forecasting Bitcoin returns: Is there a role for the USChina trade war? Journal of Risk, 23(3), 75-93. https://doi.org/10.21314/JOR.2021.001

Platanakis, E., \& Urquhart, A. (2020). Should investors include Bitcoin in their portfolios? A portfolio theory approach. The British Accounting Review, 52(4), 100837. https://doi.org/10.1016/j.bar.2019.100837

Popper, N. (2015). Digital gold: The untold story of Bitcoin. Penguin Books Limited.

Poyser, O. (2019). Exploring the dynamics of Bitcoin's price: a Bayesian structural time series approach. Eurasian Economic Review, 9(1), 29-60. https://doi.org/10.1007/s40822-018-0108-2

Qin, M., Su, C. W., \& Tao, R. (2021). BitCoin: A new basket for eggs? Economic Modelling, 94, 896-907. https://doi.org/10.1016/j.econmod.2020.02.031

Shahzad, J., Bouri, E., Roubaud, D., Kristoufek, L., \& Lucey, B. (2019). Is Bitcoin a better safe-haven investment than gold and commodities. International Review of Financial Analysis, 63, 322-330. https://doi.org/10.1016/j.irfa.2019.01.002

Sharpe, W. F. (1964). Capital asset prices: A theory of market equilibrium under conditions of risk. Journal of Finance, 19(3), 425-442. https://doi.org/10.1111/j.1540-6261.1964.tb02865.x

Shevchenko, D., \& Godwin, E. I. (2018). The effects of behavioral factors on the creditworthiness of small-scale enterprises. In I. Nekrasova, O. Karnaukhova, \& B. Christiansen (Eds.), Fractal approaches for modeling financial assets and predicting crises. IGI Global. https://doi.org/10.4018/978-1-5225-3767-0.ch006

Shukur, G., \& Mantalos, P. (1997). Size and power of the RESET test as applied to systems of equations: A bootstrap approach (Working Paper). Department of Statistics, University of Lund.

Shukur, G., \& Mantalos, P. (2000). A simple investigation of the Granger-Causality test in integratedcointegrated VAR systems. Journal of Applied Statistics, 27, 1021-1031. https://doi.org/10.1080/02664760050173346

Smales, L. A. (2014). News sentiment and the investor fear gauge. Finance Research Letters, 2(11), 122-130. https://doi.org/10.1016/j.frl.2013.07.003

Smales, L. A. (2019). Bitcoin as a safe haven: Is it even worth considering. Finance Research Letters, 30, 385-393. https://doi.org/10.1016/j.frl.2018.11.002

Stavroyiannis, S., \& Babalos, V. (2017). Dynamic properties of the Bitcoin and the US market. SSRN. https://doi.org/10.2139/ssrn.2966998

Su, C. W., Cai, X. Y., Qin, M., Tao R., \& Umar, M. (2021a). Can bank credit withstand falling house price in China. International Review of Economics \& Finance, 71, 257-267. https://doi.org/10.1016/j.iref.2020.09.013

Su, C. W., Khan, K., Tao R., \& Moldovan, N. C. (2019a). Does geopolitical risk strengthen or depress oil prices and financial liquidity? Evidence from Saudi Arabia. Energy, 187, 116003. https://doi.org/10.1016/j.energy.2019.116003

Su, C. W., Qin, M., Rizvi, S. K. A., \& Umar, M. (2020a). Bank competition in China: A blessing or a curse for financial system. Economic Research-Ekonomska Istraživanja, 34(1), 1244-1264. https://doi.org/10.1080/1331677X.2020.1820361 
Su, C. W., Qin, M., Tao, R., \& Umar, M. (2020b). Does oil price really matter for the wage arrears in Russia? Energy, 208, 118350. https://doi.org/10.1016/j.energy.2020.118350

Su, C. W., Qin, M., Tao, R., \& Umar, M. (2020c). Financial implications of fourth industrial revolution: Can bitcoin improve prospects of energy investment? Technological Forecasting and Social Change, 158, 120178. https://doi.org/10.1016/j.techfore.2020.120178

Su, C. W., Qin, M., Tao, R., Nicoleta-Claudia, M., \& Oana-Ramona, L. (2020d). Factors driving oil price - From the perspective of united states. Energy, 197, 117219.

https://doi.org/10.1016/j.energy.2020.117219

Su, C. W., Qin, M., Tao, R., Shao, X. F., \& Lucian, L. A. (2019b). Can Bitcoin hedge the risks of geopolitical events. Technological Forecasting and Social Change, 159, 120182. https://doi.org/10.1016/j.techfore.2020.120182

Su, C. W., Qin, M., Zhang, X. L., Tao, R., \& Umar, M. (2021b). Should Bitcoin be held under the U.S. partisan conflict? Technological and Economic Development Economy, 27(3), 511-529. https://doi.org/10.3846/tede.2021.14058

Su, C. W., Song, Y., Tao, R., \& Hao, L. N. (2020e). Does political conflict affect bilateral trade or vice versa? Evidence from Sino-U.S. relations. Economic Research-Ekonomska Istraživanja, 33(1), 32383257. https://doi.org/10.1080/1331677X.2019.1694559

Su, C. W., Sun, T. Z., Ahmad, S., \& Mirza, N. (2021c). Does institutional quality and remittances inflow crowd-in private investment to avoid Dutch Disease? A case for emerging seven (E7) economies. Resources Policy, 72, 102111. https://doi.org/10.1016/j.resourpol.2021.102111

Su, C.-W., Huang, S.-W., Qin, M., \& Umar, M. (2021d). Does crude oil price stimulate economic policy uncertainty in BRICS? Pacific Basin Finance Journal, 66, 101519. https://doi.org/10.1016/j.pacfin.2021.101519

Tao, R., Su, C. W., Xiao, Y. D., Dai, K., \& Khalid, F. (2021). Robo advisors, algorithmic trading and investment management: Wonders of fourth industrial revolution in financial markets. Technological Forecasting and Social Change, 163, 120421. https://doi.org/10.1016/j.techfore.2020.120421

Troster, V., Tiwari, A. K., Shahbaz, M., \& Macedo, D. N. (2019). Bitcoin returns and risk: A general GARCH and GAS analysis. Finance Research Letters, 30, 187-193.

Wang, G. J., Tang, Y. P., Xie, C., \& Chen, S. (2019). Is Bitcoin a safe haven or a hedging asset? Evidence from China. Journal of Management Science and Engineering, 4(3), 173-188. https://doi.org/10.1016/j.jmse.2019.09.001

Whaley, R. E. (2000). The investor fear gauge: Explication of the CBOE VIX. Journal of Portfolio Management, 26(3), 12-17. https://doi.org/10.3905/jpm.2000.319728

Weber, B. (2014). Bitcoin and the legitimacy crisis of money. Cambridge Journal of Economics, 40, 17-41. https://doi.org/10.1093/cje/beu067

Yermack, D. (2013). Is Bitcoin a real currency? An economic appraisal (NBER Working Paper No. 19747). National Bureau of Economic Research. https://doi.org/10.3386/w19747

Zaghloul, E., Li, T., Mutka, M., \& Ren, J. (2019). Bitcoin and blockchain: Security and privacy. arXiv:1904.11435.

Zhu, Y., Dickinson, D., \& Li, J. (2017). Analysis on the influence factors of Bitcoin's price based on VEC model. Financial Innovation, 3, 3. https://doi.org/10.1186/s40854-017-0054-0

Zouaoui, M., Nouyrigat, G., \& Beer, F. (2011). How does investor sentiment affect stock market crises? Evidence from panel data. Financial Review, 46(4), 723-747.

https://doi.org/10.1111/j.1540-6288.2011.00318.x 